Opinion

\title{
A Practical External Penile Prosthesis
}

\author{
Mingguang $\mathrm{Yi}^{*}$ \\ Retired Electronics Engineer, Australia
}

*Corresponding author: Mingguang Yi, Retired electronics Engineer, 12 Marwood Ave, Truganina, VIC, 3029, Australia, Email:1678845810@qq.com

To Cite This Article: Mingguang Yi. A Practical External Penile Prosthesis. Am J Biomed Sci \& Res. 2021 - 12(5). AJBSR.MS.ID.001795.

DOI: 10.34297/AJBSR.2021.12.001795.

Received: 畊 April 24, 2020; Published: 盎 April 30, 2021

\begin{abstract}
Current external penile supports are not accepted by most women because they are rigid and can cause a strong foreign body sensation in the vagina. In order to improve women's overall satisfaction, a flexible support called the "band external penile prosthesis" is proposed, which consists of only one piece of corrugated paper buried between two medical silicone tapes.
\end{abstract}

Keywords: Erectile Dysfunction, External Penile Support, External Penile Prosthesis

\section{Opinion}

Since the beginning of the last century, many efforts have been made to design external penile support devices for the treatment of erectile dysfunction (ED) [1-3]. However, so far, no external support device has been widely used. Current penile support devices are mostly rigid and can cause a strong foreign body sensation (FBS) in the vagina. In order to improve the overall satisfaction of women, this article proposes a flexible support, called band external penile prosthesis (EPP), which consists of only a piece of corrugated paper buried between two medical silicone tapes [4], as shown in Figure 1a. Actual tests show that when it is rolled into a tube, its supporting force exceeds 10 kilograms.

(a)

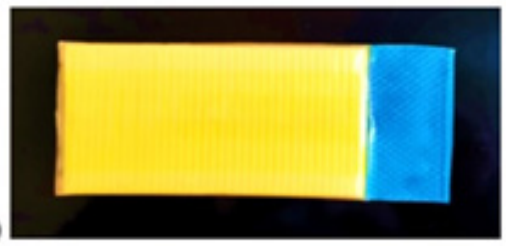

(b)

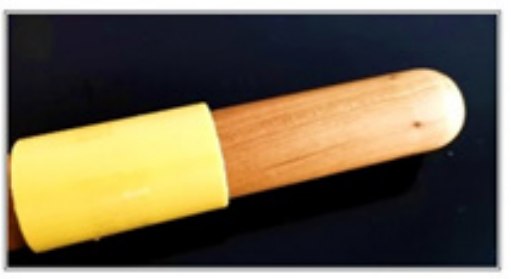

Figure 1: The band EPP

a) Band EPP sample with a size of $120 \mathrm{~mm} \times 58 \mathrm{~mm}$.

b) Wrapped on the penis. 
The use of band EPP is very convenient. Just remove the cover of the sticker area, wrap the EPP tightly on the penis shaft, and stick it firmly, as shown in Figure 1b. The only problem is that the pubic hair may be tangled or stuck. To avoid troubles caused by pubic hair, it is best to cut it short. The comfort of band EPP is better than that of rigid support. In fact, the band EPP in use is like a penis sleeve, which not only provides strong longitudinal support, but also provides a suitable size lumen, so it also provides strong tactile stimulation for the penis [5]. In addition, the strong longitudinal support will greatly reduce the patient's sexual anxiety and enhance the patient's self-confidence. Band EPP has good size adaptability.

No need to customize. Several sizes can cover most patients. The author believes that band EPP may be the ultimate solution for EPP because it cannot be simpler or better.

\section{Acknowledgement}

This research received no specific grant from any funding agency in the public, commercial, or not-for-profit sectors.

\section{Disclosure}

The author declares no conflict of interest in preparing this article. This study is the author's independent research. There is no any interest to disclose.

\section{References}

1. Louis B Hawley (1907) Surgical appliance. Patent US 844: 798.

2. Laurence A Levine (2004) External devices for treatment of erectile dysfunction. Endocrine 23(2-3): 157-160.

3. Stein MJ, Lin H, Wang R (2014) New advances in erectile technology. Ther Adv Urol 6(1): 15-24.

4. Mingguang Y (2021) Band External Penile Prosthesis. Patent CHN 2021205580259, Australia.

5. Wassersug R, Wibowo E (2017) Non-pharmacological and non-surgical strategies to promote sexual recovery for men with erectile dysfunction. Transl Androl Urol 6(Suppl 5): S776-S794. 